the standpoint of experimental pharmacology, the publication of this pocket handbook has done a service to the student and practitioner of medicine. Therapeutics tend to be neglected in hospital work so that everyone is apt to forget that outside the ward-door the weapons of the doctor still consist in large part of drugs. It is therefore essential that there should be readily available concise information on the action of drugs.

The student will become much more expert in the treatment of the sick if during his hospital rounds he makes frequent reference to such a book as this. The arrangement of subject matter, notoriously difficult. is probably the best that could be used. A further advantage is the blank page interleaving, allowing notes to be made of the views and idiosyncrasies of various teachers. For the general practitioner also the book should be of considerable interest.

\section{TEXTBOOK OF EXPERIMENTAL SURGERY.}

By J. Markowitz, M.B., Ph.D., Research Associate, Dept. of Physiology, University of Toronto. London. Baillière, Tindall \& Cox. 1937. Pages 528. Price 31s. 6d.

This remarkable book should appeal to three distinct groups of scientific workersto experimental physiologists, to clinicians and to veterinary surgeons-for it is a carefully compiled and beautifully illustrated textbook of operations upon the lower animals. When it is realized that these procedures must be carried out under well-regulated anæsthesia and the strictest aseptic precautions, it becomes easy to understand how one of the first experimental laboratories run on these lines became a great veterinary hospital.

The steps of the many intricate operations are described in sufficient detail to enable other experimenters to adopt them in their practice; and since the principles are the same as those which govern human surgery it is to be hoped that a training in this type of work may prove of value in developing technical skill among young surgeons. The ingenuity displayed by the experimenters in devising operations on the alimentary and vascular systems calls for special remark, and here the application of the findings of physiological experiments to the problems of human physiology and therapeutics is at once obvious. The book can therefore be read with much benefit by students working for examinations in human physiology and pharmacology.

The volume contains accounts of experiments bearing on peptic ulceration, intestinal obstruction, peritonitis, biliary fistula and liver function, coronary occlusion, the pituitary body and the autonomic nervous system; and there are also descriptions of the methods and results of transplanting bone, fascia and whole organs such as the kidney. This list may provide some indication of the scope of the work, and of its value to the practising surgeon. Its value as a guide to those interested in any particular subject is greatly enhanced by the carefully selected bibliography at the end of every chapter, and we would like to add a final word of congratulation to the author for compressing a large amount of material into a book of reasonable size.

NEURO-OPHTHALMOLOGY.

By R. Lindsay Rea, B.Sc., M.D., F.R.C.S. Heinemann. 1938. Price 42s.

For the physician, be he a specialist in neurology or not, Medical Ophthalmoscopy by Gowers remains a classic. It has the defect, however, as its title implies, that it is limited to the consideration of fundal changes, important as these undoubtedly are, and does not deal with other directions in which examination of the eye may help in the diagnosis and localization of disease.

True there have been volumes published since then which have attempted to remedy this defect and most modern manuals of physical diagnosis embrace this field. However, an up-to-date, comprehensive and well illustrated book by an ophthalmologist who is in constant touch with the physician, and, thus can appreciate his outlook, is always welcome. Of such a type of book Neuro-Ophthalmology is a good example.

Mr. Lindsay Rea passes in review the pupil and its reactions, the muscles of the eye and the changes in the optic nerve, the macula and the retina. The localizing value of ocular symptoms in the diagnosis 